\title{
HUMAN ECONOMIC SECURITY
}

\section{Dr. P.Tsagaan}

It should be pointed out that the concept, of economic security, especially regarding human economic security itself is a controversial one. There is different definition and concept on individual, national, regional and global economic security.

Our politicians as well as NGO's like-Consumers' Association have been talking about the human security for a long time, but in a vague and broad sense.

Politicians as well as pseudo-strugglers for well-being of people not only politicize any economic issue, but also securitize it, especially, before or during any election in Mongolia. Therefore, definition of economic security, in particular definition of human economic security should be used very carefully. It should be used within the limits of commonly accepted meanings and limits.

Human economic security issue should be considered in a narrow context, in other words, in terms of basic human needs. Scholars, such as - Barry Buzan, Ole Waever, Jaap de Wilde has defined five basic needs necessary for human life:

1. Adequate food;

2. Water;

3. Clothing;

4. Shelter;

5. Education.

Having mentioned the above five needs, I must emphasize that they can not be securitized, unless, they have an importance of survival caused by threats or severe vulnerabilities. In another word, if there is neither existential quality ${ }^{1}$ nor threat to human being, they have to be normal social and economic issues. Government, national and local politicians may talk about the level of welfare of the population including security issue in case of necessity.

- Adequate food. In 1995, according to World Bank measurement 36 per cent' of the Mongolia's population lived in poverty. Therefore, the World Bank (loan) and UNDP (grants) have been most active partners of Government in poverty alleviation in the Mongolia. No doubt, there is a progress in poverty' alleviation, but it is slow. Nevertheless, almost one third of population still lives in poverty, which was determined

P.TSAGAAN is Vice President of Premier International. Inc. 
by the Government. Many foreign countries first of all Japan has extended extra commodity and food aid to Mongolia in early 1990s. There is a huge potential in Mongolia not only to eliminate malnutrition and feed them, but also to export agricultural and dairy produce in future. One vivid and successful example of the Green revolution as well as production of dairy produce - cheese. The purpose of the Green revolution started in 1997 was to secure an adequate food supply to the people. With small input from the Government, the UNDP and other donors the number of families participating in the Green revolution has increased from 70000 in 1997 to 116000 in 1999. Mongolia's food supply has diversified and price in general has stabilized.

According to statistics, two thirds of an average family income: is disbursed on food. Therefore, we have low savings, investment, job opportunity and low living standards.

- Water. Clean and, sufficient potable water is vital. The Constitution (1992) and Civil Code of Mongolia (1994) provisions that water reserves are state property. Thus, water on and under soil cannot be in a private ownership. According to the Law on Water (1995) and related Government resolutions, one of the primary duties of Governors of sound and districts are to ensure supply of water that meets sanitary requirements. But in reality $38,5 \%$ of inhabitants, living in rural areas use water that does not meet sanitation requirements. $10 \%$ of wells in rural areas do not meet required standards (WASH 21 Project, June 1999). Shortly, water supply and sanitation in Mongolia is lagging far behind.

- Clothing. All human beings, especially those who live in harsh climatic conditions need clothing to protect the body against extreme weather (cold, hot, winds etc). In this regard, Mongolians dress in both western and national clothing needed for four seasons: cold winter, hot summer, windy spring and rainy fall.

- Shelter. A man and his family need a shelter. Total housing stock in Mongolia is 6, 3 mln.sq.m (p. 149 "Mongolian Statistical Yearbook 1998 " published by National Statistical Office 1999). It means that 2, 6 esq. per capita. However, the square is unevenly distributed in urban and rural areas, where most herders live in traditional germ tents. Public investment in residential housing projects was stopped in 1991. State 
owned housing was privatized to tenants free of charge from 1997. According to latest statistics, over $90 \%$ of housing has been privatized so far. It should be pointed out that housing privatization helped to trigger small business boom in urban areas.

One of sad social phenomena is street or stray children. According to police report, there were 1028 stray children in 1997 in Mongolia. As of April 2000, this number now is 934 , and 769 or $82,3 \%$ of them are in Ulaanbaatar city and the rest are in 21 images. 573 children are being sheltered in 19 Care centers run by foreigners, 161 children are taken care by national Labor education centers. Unfortunately, about 300 children are surviving in manholes.

- Education. Under present world situation and development trend, education, especially, primary education is crucial to needs of human economic security. Illiterate person is like a blind man lost in the forest of globalization. Education is a key factor in obtaining job and income, which is the main source for human basic needs. Educated person is more capable to adopt new challenges, than, illiterate person is. Under socialism, education was traditionally considered one of the priority sectors in terms of the national budgetary allocations. This policy continued throughout the transition period despite sharp decline and fluctuations in economy in early 1990s.

The expenditure on education sector remains the largest item in terms of both the budget allocations and the GDP percentage: $17,1 \%$ of the total budget expenditures and 6, 8 of GDP in 1998.

- Art. 33 of the Law on Education require that not less than 20 percent of state budget should be allocated for education. Except for fiscal year 1992, this provision was not implemented. The Government education expenditure in current prices increased from year to year during the 1990s, but in real terms, they have been negative until 1999. At the same time, private sector contribution, to education sector has been growing gradually. Although, private sector investment has not been fully covered by national statistics. The number of graduates of domestic higher educational institutions increased from 38000 in 1995 to 65 000 in 1998.

Literacy rate of adults is relatively very high in Mongolia (over 95\%). Mongolian citizens enjoy the right to get basic education- free of charge. However, widespread school dropouts continued, in rural areas until mid of $1990 \mathrm{~s}$ 
due to economic shocks and deterioration of living standards caused by collapse of planned economy, overnight stop of Soviet aid and de-facto bankruptcy of state etc.

\section{Education-Job-Income is the Triangle of Human Economic Security}

Income is the output of education and employment, and the very precondition for the economic security. Despite the GDP growth for the last 5 years, Mongolia has remained one of the leading ODA recipient countries in the world, due to low income per head as percentage of GDP in comparison to other countries.

There are two important points to be highlighted. Firstly, there is a linkage between the human economic security and other security issue. Secondly, there is a boundary between politicization and securitization of economic issues, but difficult to identify. Securitization is the extreme form of politicization.

Failures of economic actors (government, companies) may lead to the concern of human economic security. If a company is dissolved because of bankruptcy, then the workers will be laid off and unemployment will sour. Insolvency of a given company usually is not related to human economic security issue, unless the company's dissolution has an immediate adverse impact on individuals. Technically a state can go bankrupt as a company. Two well-known examples. In the late 1980s and early 1990s Mongolia lost its whole foreign reserves, and as you all know - the Mexican debt crisis. But the state can not be dissolved as a company and its citizens can not be sacked. And what happens in this case? Mass unemployment, devaluation of national currency, public dissatisfaction with authorities, migration to other countries and so forth. According to press, more than 30000 Mongolian 'citizens, many of them illegally, live and work in other countries.

We, Mongolians are becoming a part of the global economy. Whether we want it or not the process of globalization has reached our remote country. During the last ten years, while we have been trying to shift from centrally planned economy to market economy, the world process of globalization of trade, finance, information has gone far ahead. New information technologies, first of all Internets, liberalization policy, new requirements of WTO, rapidly growing private investment flow have accelerated the progress.

What we have to do in order to ensure, human economic security in Mongolia in a completely new environment of world market and competition? (By the way, there is a difference between the definition "human" and "citizen" 
from legal point of view. However, here the word "human" is used in the meaning of citizen of Mongolia).

We have to talk about security only if there is a direct threat; Therefore, we have to think - when does the scale of threat become sufficient to count as a legitimate security issue. Recently, BBC and CNN reported about famine in Mongolia, because of Zed (severe snowstorm). If it corresponds to reality then the Government must think of it, and define how to cope with the famine and its consequences.

\section{Conclusions and Recommendations}

- Human economic issues can be considered and solved, in a context of normal economic and social policy of a given country.

- Genuine human economic security issue is relatively rare. But human economic issue can be politicized under certain conditions in context of politics, critiques especially before or during special events like election campaign, budget approval etc. for different political and other purposes.

- There are many unresolved economic and social issues in Mongolia such as, malnutrition, high level of poverty, unemployment, usage of unsafe water, poor housing conditions, school dropouts, low quality of education.

- Despite economic, social problems and landlocked position, globalization process has reached Mongolia.

- Under new circumstances Government of Mongolia should adhere to the following policy in order to secure human economic security:

1. To improve its competitiveness in broad sense (in terms of economy, public and private sector management, human development etc.) and in order to be able to compete with other nations in terms of efficiency and productivity. This is the strategy of the nation and the most efficient way to resolve human economic security related issues.

2. Government should firmly continue reform policies in coming years regardless of election results. It means that privatization of land, transparent and early privatization of most valued enterprises, downsizing and reform of public sector finance and management, efficiency in services, but it does not promote legalization of red tape, bureaucracy, corruption and officialdom.

3. To accelerate the education reform towards high-tech skills and quality. 
4. To take advantage of globalization for penetration into outside market by supporting potential export- oriented sector, which might compete on the international market, such as, cashmere, meat, information technology, and tourism and so forth.

5. To create stable, fair policy environment conducive to national private sector led economy and foreign direct investment. It includes predictable and low tax' on income, efficient tax collection, independent, fair and efficient judiciary ensuring rule of law and healthy financial sector.

6. To elaborate and pursue a special Rural Development Policy (To treat and maintain health standards of herders and livestock, sanitation and purification of drinking water using solar or wind energy).

Human economic security will be vulnerable until Mongolia has gained its economic independence. Why? Because, we used to be dependent on generous aid and loans provided by the Soviet Union and COMECON until 1990. Since then, we have been dependent on multilateral and bilateral donors' assistance and loans. In the past, during socialism approximately 70 per cent of budget expenditure and domestic investment had been channeled from the USSR and its allies. Now 30 percent is received from donor communities. The difference between past and present is not only in difference of figures and percentage. In the past the figure on debt and borrowing was considered as a state secret and public had no idea about them, and thought that Mongolia had no debt to foreign country. But now, all the figures are open to public, and all our citizens are well aware of them.

This is true that unless we gain our economic independence in coming years, our citizen's well-being and economic security will remain dependent on others and vulnerable on changes in other countries' policy and economy. 